\title{
ANALISIS KEUNTUNGAN PEDAGANG DAGING BABI BERDASARKAN PREFERENSI KONSUMEN DI PASAR TRADISIONAL KOTA MANADO
}

\author{
Octavino M.V. Osak, V.V.J. Panelewen, T. D.F. Lumy* dan F.N.S Oroh
}

Fakultas Peternakan, Universitas Sam Ratulangi Manado, 95115

\begin{abstract}
ABSTRAK
Penelitian ini bertujuan untuk menganalisis tingkat keuntungan usaha dan kemampuannya dalam menghasilkan laba (profitabilitas) pada bisnis pedagang daging babi di pasar tradisional Kota Manado. Penelitian ini dilaksanakan dengan menggunakan metode survey, di mana metode penentuan sampel dilakukan secara secara sengaja (purposive sampling) teradap 31 pedagang daging babi dipasar tradisional. Analisis yang digunakan adalah analisis rasio penerimaan-biaya atau RC Ratio (revenue-cost ratio) dan perhitungan margin keuntungan. Berdasarkan hasil penelitian diketahui bahwa rata-rata keseluruhan biaya usaha pedagang pengecer komponen daging babi per minggu sebesar Rp.22.558.822 dengan total keseluruhan biaya usaha pedagang pengecer daging babi per minggu sebesar Rp.699.323.491. Jumlah penjualan karkas dan non karkas ternak babi berdasarkan preferensi konsumen rata-rata sebanyak $398 \mathrm{Kg} /$ minggu atau 70,40 persen, sedangkan non karkas terjual rata-rata sebanyak $168 \mathrm{Kg} /$ minggu atau 29,60 persen. Jumlah hasil penjualan berdasarkan preferensi konsumen di pasar tradisional di Kota Manado sebanyak Rp.848.890.000 per minggu dengan rata-rata sebesar Rp.27.383.548,39/minggu setiap pedagang. Jumlah keuntungan pedagang sesuai jumlah penjualan berdasarkan preferensi konsumen baik karkas maupun non karkas ternak babi per minggu di pasar
\end{abstract}

*Korespondensi (corresponding aouthor): Email: tilly_lumy@yahoo.co.id tradisional Kota Manado sebanyak Rp848.890.000 setiap minggu atau rata-rata sebanyak Rp27.383.548,39 setiap minggu masing-masing responden. Besarnya gross profit pedagang daging babi sebesar Rp149.566.509 per minggu atau rata-rata sebesar Rp4.824.726 per minggu, sedangkan Gross Profit Margin yaitu menggambarkan kemampuan dalam mendapatkan laba berdasarkan jumlah penjualan, yaitu sebesar $18 \%$ yang berarti rata-rata jumlah penjualan baik karkas maupun non karkas daging babi menurut preferensi konsumen memberikan gross profit sebesar 18 persen per minggu.

Kata kunci: Keuntungan, preferensi konsumen, pedagang daging babi.

\section{ABSTRACT}

\section{PROFIT ANALYSIS OF PORK RETAILERS BASED ON CONSUMER PREFERENCES IN TRADITIONAL MARKETS IN MANADO CITY.This study} aims to analyze the level of profit and its ability to generate profit (profitability) by the pork retailers on traditional markets in Manado City. This research was conducted using a survey method, where the sampling method was purposive sampling toward 31 samples of pork seller. To meet the goal of this studi, revenue cost ratio and profit margin analysis was implied. Based on the results of the study it was found that the average overall cost of the business of retailers of pork components per week was IDR.22,558,822. with a total total cost of IDR. 699,323,491. The amount of carcass and non carcass sales 
of pigs based on consumer preferences averaged $398 \mathrm{Kg} /$ week or 70.40 percent, while non carcasses sold an average of $168 \mathrm{Kg} /$ week or 29.60 percent. The amount of sales based on consumer preferences in traditional markets in the city of Manado was IDR.848,890,000 per week with an average of IDR.27,383,548.39/week per retailer. The amount of profit according to the number of sales based on consumer preferences both carcass and non carcass of pig per week in the traditional market of Manado City was IDR.848,890,000 per week or an average of IDR.27,383,548.39 per week for each retailer. The amount of gross profit of pork retailers in the traditional market of Manado City was IDR.149,566,509 per week or an average of IDR.4,824,726 per week, while Gross Profit Margin was an ability to obtain profits based on the number of sales, which was $18 \%$, which means average the average sales of both carcasses and non carcasses of pork according to consumer preferences provide gross profit of 18 percent per week.

Keywords: Profit, consumers preferences, pork retailers.

\section{PENDAHULUAN}

Dalam rangka mewujudkan peternakan yang berbasis agribisnis maka pengembangan peternakan merupakan alternatif yang perlu diperhitungkan dengan didasarkan pada data dan sumberdaya (Sajow et al., 2014). Data pada tahun 2016 menunjukkan bahwa total produksi daging tahun 2015 sebanyak 3,06 juta ton yang terdiri dari ayam ras pedaging 1,63 juta ton, daging sapi dan kerbau 0,54 juta ton, babi 0,33 juta ton, ayam buras 0,30 juta ton, kambing dan domba 0,11 juta ton, ayam ras petelur 0,10 juta ton dan ternak lainnya 0,04 juta ton. Sedangkan produksi daging terbesar disumbang oleh ayam ras pedaging yaitu 53,3persen, sapi dan kerbau 17,7 persen, babi 10,8 persen dan ayam buras 9,8 persen (Ditjennakkeswan, 2016). Dari data tersebut terlihat bahwa produksi daging babi di Indonesia menempati urutan ketiga setelah daging ayam ras pedaging dan daging sapi/kerbau.

Di Indonesia, populasi babi terkonsentrasi pada beberapa daerah antara lain di Bali, Sumatera, Jawa, Kalimantan, Nusa Tenggara Timur (NTT), Sulawesi dan Papua (Soewandi dan Talib, 2015). Sulawesi Utara salah satu daerah sentra produksi ternak babi, dengan jumlah produksi ternak babi tahun 2017 sebanyak 414.653 ekor (BPS, 2018). Hal ini menunjukkan ternak babi merupakan salah satu komoditas ternak yang dominan dan perlu dikembangkan, serta mendapat perhatian pemerintah karena mampu menghasilkan produk daging untuk memenuhi pangan asal ternak bagi masyarakat.

Pengembangan dan meningkatkan produktivitas usaha ternak babi diperlukan bagi pelaku usaha dengan mempertimbangkan faktor peluang bisnis sesuai jumlah penjualan dan permintaan daging babi, termasuk kondisi pedagang babi, baik di pasar swalayan dan 
semi modern (pasar segar), maupun pasar tradisional.Sistem penjualan daging dibedakan berdasarkan ada tidaknya penggolongan kualitas atau grading pada daging yang dijual (Arifin, et al., 2016). Potongan komponen karkas berbeda-beda dari satu tempat ketempat lain sesuai dengan sistem pemotongan untuk dijual dan kebiasaan masyarakat, termasuk potongan karkas dan kepala ternak babi di Sulawesi Utara khususnya di Kota Manado.

Karkas menurut Ovi (2011) adalah bagian tubuh yang telah mengalami proses pemotongan tanpa kepala, keempat kaki bagian bawah mulai dari carpus dan tarsus, kulit, darah dan organ dalam (hati, saluran pencernaan, jantung, saluran reproduksi, paruparu, limpa kecuali ginjal). Berat karkas olahan yaitu tanpa organ internal (kecuali ginjal dan jaringannya), kepala, bagian bawah kaki, tulang belakang dan organ genital (Petrovićet al, 2017).

Karkas babi adalah bagian dari tubuh babi sehat yang telah dipotong, dikerok bulunya, dipisahkan kepala dan kakinya, serta dikeluarkan jeroannya. Karakter karkas babi menunjukkan rasio daging-tulang sebesar 2,95 dan rasio daging berlemak-non lemak sebesar 0,17 (Thomas, et al., 2017).

Preferensi konsumen terhadap daging merupakan pilihan suka atau tidak suka oleh seseorang terhadap produk daging yang
dikonsumsi.Konsumen

memperhatikan

berbagai macam atribut yang melekat pada daging yang dijadikan sebagai pertimbangan dalam pengambilan keputusan membeli.Menurut Sumarwan (2004) perilaku konsumen akan sangat terkait dengan atribut produk. Atribut produk adalah karakteristik dari suatu produk yang menjadi pertimbangan konsumen dalam membeli suatu produk. Oleh sebab itu perlunya penelitian mengenai preferensi konsumen menurut potongan komponen tubuh ternak yaitu daging, kepala, keempat kaki bagian bawah, darah dan organ dalam (jeroan) dan tetelan, terhadap keuntungan yang diperoleh pedagang daging babi di pasar tradisional di Kota Manado.

Berdasarkan latar belakang maka dapatlah dirumuskan masalah penelitian sebagai berikut:

1. Berapa banyak hasil penjualan menurut preferensi konsumen berdasarkan komponen daging babi di pasar tradisional Kota Manado.

2. Seberapa besar profitabilitas atau kemampuan dalam mendapatkan laba berdasarkan jumlah penjualan daging babi di pasar tradisional Kota Manado.

\section{METODE PENELITIAN}

Tempat dan Waktu Penelitian 
Penelitian ini untuk menganalisis tingkat keuntungan usaha dan kemampuannya dalam menghasilkan laba (profitabilitas) pada bisnis pedagang daging babi di pasar tradisional Kota Manado, yaitu Pasar Pinasungkulan di Karombasan dan Pasar Bersehati di Calaca.Penelitian survei dilaksanakan selama satu bulan, yaitu bulan November tahun 2018 .

\section{Jenis dan Sumber Data}

Sumber data yang dikumpulkan yaitu data primer dan data sekunder.Penelitian menggunakan data primer yaitu data yang diperoleh dari pengamatan langsung di lapangan. Data primer penelitian ini terdiri dari :identifikasi pemilik usaha pedagang babi, biaya-biaya produksi yang dikeluarkan, jumlah penerimaan dan umlah keuntungan usaha pendagang daging babi.Sedangkan data sekunder diperoleh dari instansi-instansi terkait yang ada hubungannya dengan penelitian ini.

\section{Teknik Pengumpulan Data}

Penelitian ini dilaksanakan dengan menggunakan metode survey menurut petunjuk Singarimbun dan Effendi (1995) dan Sugiyono (2004).Penentuan pedagang daging babi sebagai sampel responden dilakukan secara secara sengaja (purposive sampling) dengan kriteria yaitu padagang daging babi tetap (tidak musiman) dan lama usaha minimal 1 tahun di pasar Pinasungkulan Karombasan dan Pasar Bersehati Calaca Kota Manado.Metode pengambilan data menurut petunjuk Hidayatullah, et al.(2011) yaitu wawancara secara mendalam kepada responden berdasarkan daftar pertanyaan (questionairres) yang telah disusun sesuai dengan objektif kajian.

\section{Metode Analisis}

Untuk mengetahui kemampuan bisnis pedagang daging babi dalam memperoleh laba (profit), digunakan rasio penerimaan-biaya atau RC Ratio (revenue-cost ratio) dan perhitungan margin keuntungan atau GPM (gross profit margin) menurut Taruh (2012), dengan formula sebagai berikut:

Gross Profit $=$ Total Revenue - Total Cost

Atau $\pi=$ TR - TC

$$
R C \text { Ratio }=\frac{\text { Revenue }}{\text { Cost }}
$$

dan

$$
\begin{array}{ll}
\text { Gross profit margin (GPM) } & \text { Gross profit } \\
\cline { 2 - 2 } & \text { Net sales }
\end{array}
$$

\section{Dimana :}

$\Pi$ atau Gross Profit yaitu keuntungan diperoleh dari penerimaan total dikurangi biaya totalpemasaran di tingkat pedagang daging babi tidak termasuk biaya tidak langsung lain dalam usaha pedagang daging babi.

RC Ratio adalah perbandingan antara penerimaan dengan biaya total (biaya 
pemasaran total) dalam usaha pedagang daging babi.

Gross Profit Margin(GPM) adalah margin keuntungan yaitu perbandingan antara keuntungan (Profit) dengan jumlah penjualan (Net Sales) usaha pedagang daging babi.

\section{HASIL DAN PEMBAHASAN}

Penelitian ini untuk menganalisis tingkat keuntungan usaha dan kemampuannya dalam menghasilkan laba (profitabilitas) pada bisnis pedagang daging babi di pasar tradisional Kota Manado.Untuk mengetahui tingkat profitabilitas, perlu diketahui biaya dan penerimaan usaha.

\section{Biaya Usaha Penjualan Daging Babi}

Biaya usaha yang diteliti menyangkut biaya pemasaran yaitu seluruh biaya kegiatan pemasaran mulai pembelian dari produsen sampai pada tangan konsumen akhir. (Rasyaf, 2000). Biaya pemasaran yang dihitung yaitu semua pengeluaran yang harus dikeluarkan pedagang pengecer untuk memperoleh dan menjual produk komponen daging babi, sebagaimana dapat dilihat pada Tabel 1. Biaya penjualan daging babi dalam penelitian ini ialah keseluruhan biaya yang dikeluarkan oleh pedagang pengecer daging babi di pasar tradisional Kota Manado.

Tabel 1. Biaya Usaha Pedagang Daging Babi (Rp/ Minggu)

\begin{tabular}{rlrr}
\hline No & \multicolumn{1}{c}{ Uraian } & \multicolumn{1}{c}{ Jumlah } & Rata-rata \\
\hline 1 & Pembelian ternak babi & 672.883 .400 & $21.705 .916,13$ \\
2 & Biaya beli bahan/alat & - & - \\
& (1) Pisau & 432.949 & $13.966,10$ \\
(2) Telenan & 364.527 & $11.758,94$ \\
(3) Batu Asa & 187.047 & $6.033,77$ \\
(4) Blower & 5.508 & 177,68 \\
(5) LPG/Minyak tanah & 2.155 .000 & $69.516,13$ \\
& (6) Tas Plastik & 505.000 & $16.290,32$ \\
(7) Timbangan & 6.560 & 211,61 \\
3 & Sewa stan (booth) & 4.900 .000 & $158.064,52$ \\
4 & Retribusi pasar & 372.500 & $12.016,13$ \\
5 & Biaya transportasi & - & - \\
(1) Ke peternak & 7.950 .000 & $256.451,61$ \\
(2) Dari rumah ke pasar & 2.511 .000 & $81.000,00$ \\
Biaya Upah & - & - \\
(1) Tenaga kerja/pemotong & 5.050 .000 & $162.903,23$ \\
(2) Sopir & 2.000 .000 & $64.516,13$ \\
\hline Total & $\mathbf{6 9 9 . 3 2 3 . 4 9 1}$ & $\mathbf{2 2 . 5 5 8 . 8 2 2}$ \\
\hline
\end{tabular}


Biaya-biaya tersebut seperti sewa stan, tenaga kerja rata-rata per minggu

retribusi pasar, biaya transportasi, pembelian ternak babi, biaya beli bahan dan alat, serta biaya lainnya.

Biaya transportasi dibagi dua yaitu biaya transportasi pembelian ternak babi ke peternak dan biaya transportasi pedagang pergi ke pasar sudah termasuk ongkos bahan bakar kendaraan.Biaya pembelian ternak babi ke peternak sangat bervariasi yaitu Rp.200.000 - Rp350.000 per minggu.

Biaya pembelian ternak babi yang dikeluarkan oleh pedagang tergantung dari berat badan ternak babi yang dibeli.Harga pembelian daging babi per kilogram Rp30.000 - Rp40.000. Pada Tabel 1 terlihat rata-rata pedagang membeli ternak babi ke peternak sebesar Rp.21.705.916 per minggu.Biaya pembelian ternak babi dihitung jumlah berat hidup ternak babi per ekor dikali dengan jumlah ternak babi yang dibeli per minggu dikali harga harga beli per berat hidup.

Pada Tabel 1 juga terlihat biaya beli bahan/alat seperti pisau, tulenan, batu asa, timbangan, blower, LPG/minyak tanah dan kemasan plastik per minggu sebesar RP 117.954,55 per minggu. Pada tabel 1 ada juga biaya lain lain yaitu biaya upah pekerja dan biaya sewa sopir. Biaya upah tenaga kerja yang berlaku di pasar Pinasungkulan Ranotana dan pasar bersehati adalah perhari.Upah
Rp.162.903.Biaya tenaga kerja bervariasi dari Rp.100.000 sampai dengan Rp.250.000 per minggu.Terdapat beberapa responden di pasar Bersehati dan pasar Pinasungkulan tidak menggunakan jasa sewa sopir.

\section{Penjualan, Penerimaan dan Keuntungan Usaha Penjualan Daging Babi}

Komponen daging ternak babi terdiri dari karkas dan non karkas.Pengkarkasan pada ternak potong khususnya ternak babi dilakukan untukmengetahui kualitas karkas yaitu, bobotkarkas, panjang karkas dan presentase karkas (Gerungan et al 2017). Preferensi konsumen daging babi untuk penelitian ini berdasarkan komponen karkas dan non karkas untuk ternak babi, di mana karkas dibagi yaitu daging has, daging lapis,daging campur (paha dan dada), daging tetelan, lemak punggung (tawa), hati/jantung. Sedangkan non karkas terdiri dari kepala, kaki, tulang rusuk, dan tulang campur, berbeda dengan Simarmata et al (2019) mengkaji preferensi konsumen berdasarkan atributatribut daging untuk ternak broiler yaitu warna daging, warna kulit, kekenyalan kulit, aroma daging segar dan bobot daging.

Jumlah keseluruhan dan rata-rata penjualan komponen daging ternak dapat dilihat pada Tabel 2. 
Tabel 2 Jumlah Penjualan Komponen Daging Ternak Babi Berdasarkan Preferensi Konsumen (Kg/Minggu)

\begin{tabular}{|c|c|c|c|}
\hline Uraian & Jumlah & Rata-rata & $\%$ \\
\hline \multicolumn{4}{|l|}{ A. Karkas } \\
\hline 1 Daging Has & 2.291 & 74 & 13,06 \\
\hline 2 Daging Lapis & 2.205 & 71 & 12,57 \\
\hline 3 Daging Campur (Paha dan Dada) & 3.226 & 104 & 18,39 \\
\hline 4 Daging Tetelan & 1.628 & 53 & 9,28 \\
\hline 5 Lemak Punggung (Tawa) & 1.356 & 44 & 7,73 \\
\hline 6 Hati/Jantung/Paru & 1.647 & 53 & 9,39 \\
\hline Sub total A & 12.353 & 398 & 70,40 \\
\hline \multicolumn{4}{|l|}{ B. Non Karkas } \\
\hline 7 Kepala & 1.330 & 43 & 7,58 \\
\hline 8 Kaki & 1.349 & 44 & 7,69 \\
\hline 9 Tulang Rusuk & 1.366 & 44 & 7,79 \\
\hline 10 Tulang campur & 1.149 & 37 & 6,55 \\
\hline Sub total B & 5.194 & 168 & 29,60 \\
\hline Total & 17.547 & 567 & 100,00 \\
\hline
\end{tabular}

Tabel 2 menunjukkan bahwa jumlah penjualan karkas dan non karkas ternak babi berdasarkan preferensi konsumen di pasar tradisional di Kota Manado rata-rata sebanyak $567 \mathrm{Kg} /$ minggu setiap pedagang atau total sebanyak $17.547 \mathrm{Kg}$ untuk 31 responden setiap minggu. Jumlah penjualan daging babi karkas berdasarkan preferensi konsumen yaitu rata-rata sebanyak $398 \mathrm{Kg} /$ minggu atau 70,40 persen, sedangkan non karkas terjual rata-rata sebanyak $168 \mathrm{Kg} /$ minggu atau 29,60 persen.

Harga jual tiap komponen karkas dan non karkas ternak babi berbeda-beda yang tergantung antara tawar-menawar antara pedagang dan pembeli dalam transaksi antar pedagang daging babi di pasar tradisional di Kota Manado. Harga jual daging has mulai dari Rp60.000 sampai dengan Rp65.000 per kilogram. Ada juga komponen daging babi seperti lemak punggung (tawa) dan hati/jantung relatif lebih murah dibanding dengan komponen daging babi yang lain dengan harga jual Rp20.000 sampai dengan Rp30.000 per Kilogram.

Tabel 3 menunjukkan jumlah hasil penjualan berdasarkan preferensi konsumen di pasar tradisional di Kota Manado sebanyak Rp848.890.000 per minggu dengan rata-rata sebesar Rp27.383.548,39 per minggu setiap pedagang. 
Tabel 3 Penerimaan Usaha Penjualan Daging Babi (Rp/Minggu)

\begin{tabular}{|c|c|c|c|c|}
\hline No & Uraian & Jumlah & Rata-rata & $\%$ \\
\hline \multicolumn{5}{|c|}{ A/ Karkas } \\
\hline & Daging Has & 140.440 .000 & $4.530 .322,58$ & 16,54 \\
\hline 2 & Daging Lapis & 129.925 .000 & $4.191 .129,03$ & 15,31 \\
\hline 3 & Daging Campur (Paha dan Dada) & 190.120 .000 & $6.132 .903,23$ & 22,40 \\
\hline 4 & Daging Tetelan & 96.305 .000 & $3.106 .612,90$ & 11,34 \\
\hline 5 & Lemak Punggung (Tawa) & 31.915 .000 & $1.029 .516,13$ & 3,76 \\
\hline 6 & Hati/Jantung & 37.955 .000 & $1.224 .354,84$ & 4,47 \\
\hline \multicolumn{5}{|c|}{ B. Non Karkas } \\
\hline & Kepala & 43.770 .000 & $1.411 .935,48$ & 5,16 \\
\hline 8 & Kaki & 54.125 .000 & $1.745 .967,74$ & 6,38 \\
\hline & Tulang Rusuk & 63.755 .000 & $2.056 .612,90$ & 7,51 \\
\hline & Tulang campur & 60.580 .000 & $1.954 .193,55$ & 7,14 \\
\hline & Total & 848.890 .000 & 27.383.548,39 & 100,00 \\
\hline
\end{tabular}

Tabel 4 menunjukkan bahwa jumlah pendapatan atau keuntungan pedagang sesuai jumlah penjualan berdasarkan preferensi konsumen baik karkas maupun non karkas ternak babi per minggu di pasar tradisional Kota Manado sebanyak Rp848.890.000 setiap minggu atau rata-rata sebanyak Rp27.383.548,39 setiap minggu masingmasing responden.

Hasil analisis keuntungan (profit) dapat dilihat pada Tabel 4 berdasarkan rumus keuntungan (profit) :

Tabel 4 Keuntungan Pedagang Daging Babi (Rp per Minggu)

\begin{tabular}{|r|l|c|r|}
\hline No & \multicolumn{1}{|c|}{ Uraian } & Jumlah & \multicolumn{1}{c|}{ Rata-rata } \\
\hline 1 & Penerimaan (total revenue) & 848.890 .000 & 27.383 .548 \\
\hline 2 & Biaya (total cost) & 699.323 .491 & 22.558 .822 \\
\hline $\mathbf{3}$ & Keuntungan (Gross Profit) & $\mathbf{1 4 9 . 5 6 6 . 5 0 9}$ & $\mathbf{4 . 8 2 4 . 7 2 6}$ \\
\hline
\end{tabular}


Tabel 5 Gross Profit Margin Pedagang Daging Babi (Rp/Minggu)

\begin{tabular}{rlcr}
\hline No & \multicolumn{1}{c}{ Uraian } & Jumlah & \multicolumn{1}{c}{ Rata-rata } \\
\hline 1 & Keuntungan (Gross Profit) & 149.566 .509 & 4.824 .726 \\
2 & Jumlah penjualan (Net sale) & 17.547 & 567 \\
\hline \multirow{3}{*}{} & $\begin{array}{l}\text { Marjin Keuntungan (Gross } \\
\text { Profit Margin) (Rp/Kg) }\end{array}$ & \multicolumn{2}{|c}{$48.378,07$} \\
\hline
\end{tabular}

Untuk melihat aktivitas suatu usaha atau kemampuan perusahaan memperoleh keuntungan (profitabilitas) menurut Taruh (2012) dapat diukur dengan Gross Profit Margin yaitu menggambarkan kemampuan dalam mendapatkan laba. Gross Profit Margin adalah margin keuntungan yaitu perbandingan antara keuntungan (Profit) dengan jumlah penjualan (Net Sales) usaha pedagang daging babi. Penelitian ini mengkaji profitabilitas yang diukur dengan menggunakan Gross Profit Margin (GPM) yang berbeda dengan Butarbutar et al (2014) mengkaji rentabilitas pada pedagang pengecer daging sapi.

Tabel 5 menunjukkan profitabilitas berdasarkan marjin keuntungan (Gross Profit Margin) atau kemampuan usaha penjualan daging babi di pasar tradisional Kota Manado, yaitu sebesar 48.378,07 yang berarti rata-rata jumlah penjualan baik karkas maupun non karkas daging babi memberikan keuntungan atau laba (gross profit) sebesar Rp48.378,07 per kilogram dengan modal dan sumberdaya tidak termasuk biaya tidak langsung lain yang digunakan saat ini dalam usaha pedagang daging babi di pasar tradisional Kota Manado. Hasil ini menunjukkan bahwa usaha penjualan daging babi di pasar tradisional masih mampu memberikan keuntungan yang masih bersaing dalam menghadapi pesaingnya yaitu pasar modern atau pasar swalayan di Kota Manado.

\section{KESIMPULAN}

Jumlah penjualan daging babi karkas berdasarkan preferensi konsumen yaitu ratarata sebanyak $398 \mathrm{Kg} /$ minggu atau 70,40 persen, sedangkan non karkas terjual rata-rata sebanyak $168 \mathrm{Kg} /$ minggu atau 29,60 persen. Hasil analisis kemampuan dalam mendapatkan laba berdasarkan Gross Profit Margin yaitu sebesar 48.378,07 yang berarti rata-rata jumlah penjualan baik karkas maupun non karkas daging babi memberikan keuntungan atau laba sebesar Rp48.378,07 per kilogram dengan modal dan sumberdaya yang digunakan saat ini dalam usaha pedagang daging babi di pasar tradisional Kota Manado. 


\section{DAFTAR PUSTAKA}

Arifin, R., E. Rianto dan I. Susilowati, 2016. Analisis keuntungan jagal sapi di rph kota Semarang berdasarkan saluran pemasaran dan sistem penjualan. Jurnal Kesejahteraan Sosial 3(2):94103.

BPS, 2017. Populasi Ternak Menurut Kabupaten/Kota dan Jenis Ternak di Sulawesi Utara 2008-2017. BPS Sulawesi Utara, Manado. https://sulut.bps.go.id/dynamictable/ 2018/01/26/222/populasi-ternakmenurut-kabupaten-kota-dan-jenisternak-di-sulawesi-utara-20082016.html

Butarbutar, N., B. Rorimpandey, R.A.J. Legrans, dan I.D.R. Lumenta, 2014. Analisis keuntungan pedagang pengecer daging sapi di pasar tradisional Kota Manado. Jurnal Zootek 34(1):48-61.

Ditjennakkeswan, 2016.Statistik Peternakan dan Kesehatan Hewan Tahun 2016.Direktorat Jenderal Peternakan dan Kesehatan Hewan, Kementerian Pertanian, Jakarta.

Gerungan, M.S., M.Th.R. Lapian, J.A.D. Kalele dan Z. Poli, 2017. Kualitas ternak babi grower yang menggunakan tepung kulit kopi sebagai pengganti sebagian dedak pada ransum. Jurnal Zootek 37(2):386-394.

Hidayatullah, T., R.Y. Suryandari, A.C. Fitriyanto, dan I. Nahib, 2011. Pemetaan neraca dan valuasi ekonomi sumber daya pulau kecil. Journal of Society and Space 7(1):87-92.

Ovi, 2011. Karkas domba.http://ovifarm. blogspot.com/2011/06/karkas- domba.html. Diakses pada 21 Oktober 2018

Petrović, M.Z.I., R.D. Đoković, M.R. Cincović,Z. Ž. Ilić, M.D. Petrović, V. Dosković and N.R. Karabasil, 2017. Analysis of the quality of carcasses of youngsimental bulls acording to EU standard. Acta Agriculturae Serbica 22 (44):147156.

Rasyaf, M., 2009. Agribisnis Peternakan. Cetakan Ke-9. Edisi Revisi. Penebar Swadaya. Jakarta.

Sajow, A., B. Polii, dan E. Laoh. 2014. Kajian ekonomi usaha peternakan babi di Kota Tomohon (Studi Kasus). Jurnal Zootek 34(1):140-155

Simarmata, L., R.E.M.F. Osak, E.K.M. Endoh dan F.N.S. Oroh, 2019. Analisis preferensi konsumen dalam membeli daging broiler di pasar tradisional Kota Manado (studi kasus Pasar Pinasungkulan Karombasan) .Zootec 39(2):194-202

Singarimbun, M dan S. Effendi, 2011. Metode Penelitian Survei. Edisi Revisi. Pustaka LP3ES. Jakarta.

Soewandi, B.D.P. dan C. Talib. 2015. Pengembangan ternak babi lokal di Indonesia. Wartazoa 25(1):039-046.

Sugiyono, 2004. Metode Penelitian Bisnis, Cetakan Ketujuh, Penerbit CV. Alfabeta, Bandung.

Sumarwan, U. 2002. Perilaku Konsumen. Ghalia Indonesia. Jakarta.

Susilo, A., 2007. Karakteristik fisik daging beberapa bangsa babi. Jurnal Ilmu dan Teknologi Hasil Ternak 2(2):4251. 
Taruh, V., 2012.Analisis rasio keuangan dalam memprediksi pertumbuhan laba pada perusahaan manufaktur di BEI. Jurnal Pelangi Ilmu 5(1):1-11.

Thomas, R., Banik, S., Mohan, N.H. and Sarma, D.K., 2017. Carcass and meat quality of triple cross (Ghungroo $\mathrm{x}$ Hampshire $\mathrm{x}$ Duroc) fattener pigs. International Food Research Journal 24(1):153-158. 